\title{
NUEVOS DATOS SOBRE LAS INSTITUCIONES GENERADAS TRAS LA OCUPACIÓN DE LAS TEMPORALIDADES JESUITAS
}

\section{POR}

CARLOS A. MARTÍNEZ TORNERO

Universidad de Alicante

\section{RESUMEN:}

Tras la expulsión de los jesuitas de los dominios hispanos se configuraron nuevas instituciones para ocuparse de la administración de sus propiedades, pues en todo momento debían tratarse con independencia respecto a los caudales de la Real Hacienda. El presente estudio se ocupa de la descripción de tales entidades en el periodo que va desde la expulsión de 1767 hasta el restablecimiento de la Orden en 1815, eliminando la confusión existente sobre ellas y aclarando la existencia de organismos casi desconocidos hasta el momento.

\section{PALABRAS CLAVE:}

Temporalidades, Compañía de Jesús, expulsión de los jesuitas, instituciones, administración, propiedades

NEW INFORMATION ABOUT THE INSTITUTIONS CREATED AFTER THE CAPTURE OF THE BELONGINGS OF THE JESUITS

\section{ABSTRACT:}

After the expulsion of the Jesuits from the Hispanic Monarchy, new institutions were born so as to administrate their belongings, because these properties must be considered independent from the Royal 
Treasury Department. This essay pretends to describe these organizations in the period between the expulsion in 1767 to the restoration of the Society of Jesus in 1815 , clarifying the confusions about them and showing the existence of some institutions almost unknown up to the moment.

KEYWORDS:

Society of Jesus, expulsion of the Jesuits, institutions, administration, belongings, temporalities.

$\begin{array}{ll}\text { Recibido/Received } & 28-05-2010 \\ \text { Aceptado/Accepted } & 30-09-2013\end{array}$

\section{INTRODUCCIÓN}

El 27 de febrero de 1767 Carlos III firmó un real decreto por el que expulsaba de todos sus dominios a la Compañía de Jesús. La disposición se completaría posteriormente con la pragmática sanción de 2 de abril del mismo año. ${ }^{1}$ Justificaba esta medida alegando la existencia de causas muy graves que le obligaban a tomar una providencia tan rigurosa para garantizar la paz y el mantenimiento del orden dentro de su reino. Es necesario recordar que durante la primavera del año anterior tuvieron lugar revueltas populares en diferentes puntos de la península, siendo la más importante de ellas la de Madrid, conocida como el motín de Esquilache. En aquellos días el rey llegó a temer por su vida, por lo que abandonó la corte y se refugió en Aranjuez durante los siguientes ocho meses. ${ }^{2}$

${ }^{1}$ Tanto el real decreto como la pragmática sanción se pueden consultar en Coleccion general de las providencias hasta aquí tomadas sobre el estrañamiento y ocupacion de temporalidades de los regulares de la Compañia, que existian en los Dominios de S.M. de España, Indias, e Islas Filipinas á consequencia del Real Decreto de 27 de Febrero y Pragmática-Sancion de 2 de abril de 1767 [en adelante CGP], parte primera, I: 5-6 y 28-34.

${ }^{2}$ La bibliografía existente sobre la expulsión de la Compañía de Jesús de los dominios hispanos es muy vasta. Una buena muestra de ella se puede consultar en el portal temático "Expulsión y exilio de los jesuitas de los dominios de Carlos III" de la biblioteca virtual Miguel de Cervantes. Disponible en

Web: $<$ http://www.cervantesvirtual.com/bib_tematica/jesuitas/bibliografia/obras_histori a.shtml>y

$<$ http://www.cervantesvirtual.com/bib_tematica/jesuitas/bibliografia/articulos_libr os.shtml> [Consulta realizada el 28 de mayo de 2010]. 
El exilio de los jesuitas fue acompañado de la ocupación de sus temporalidades, es decir, del embargo a favor de la Corona de todas sus propiedades muebles e inmuebles, y de sus rentas eclesiásticas. La confiscación de sus posesiones no debe ser confundida con los procesos desamortizadores posteriores. Su finalidad era constituir un depósito económico con el que poder atender todos los gastos que conllevaba la expulsión. No puede, por tanto, considerarse el destierro como una medida para apoderarse de su patrimonio, pese a la campaña propagandística desarrollada por el marqués de Pombal en Portugal y recogida después por el fiscal Pedro Rodríguez Campomanes en el caso hispano, según la cual, uno de los elementos de crítica fundamentales fue el supuesto afán de riqueza de los jesuitas, señalando sus "enormes fortunas", especialmente en América.

La alusión a los grandes caudales que poseían los jesuitas en América no fue más que una leyenda, a la que se le dio fe debido a la enorme distancia entre la península y las Indias, y al hecho de que la Orden se beneficiaba de determinados privilegios fiscales, como el de la exención del pago de diezmos. ${ }^{3}$ En la mayoría de los casos, no se encontraron grandes riquezas en los colegios, sino que se hallaron cantidades poco significativas al lado de considerables deudas. No obstante, los jesuitas sí gozaron de un amplio patrimonio inmobiliario entre el que destacaron los edificios de sus colegios e iglesias. A estas posesiones habría que sumar las alhajas de sus templos, algunas obras de arte y la calidad de las bibliotecas de sus colegios.

Desde principios de la década de 1760, comenzaron a alzarse determinadas voces que hablaban de la conveniencia de limitar las adquisiciones de bienes inmuebles por parte de las llamadas manos muertas, incluida la Iglesia. Entre los que pedían esta medida se hallaban el fiscal del Consejo de Hacienda, Francisco Carrasco, y el del Consejo de Castilla, Pedro Rodríguez Campomanes.

El primero redactó una representación, fechada en 1 de junio de 1764, para la promulgación de una ley que limitase la adquisición de

${ }^{3}$ La exención del pago de diezmos fue una concesión otorgada a favor de la Compañía de Jesús por diferentes pontífices y reyes en diferentes momentos de su historia. "Real Provision de Su Magestad a consulta del Consejo, en el Extraordinario, en la qual se reducen los frutos que se cogieren en las haciendas de las Casas que fueron de los Regulares de la Compañia, á la paga integra de Diezmos á los partícipes á quienes toque su percibo por derecho", CGP, parte primera, XXIV: 68-76. 
propiedades inmobiliarias por parte del clero, pues consideraba que se trataba de un enorme perjuicio para el Estado, debido a su falta de tributación. Carrasco opinaba que la nueva legislación respetaría el patrimonio eclesiástico y su capacidad para la adquisición de bienes muebles, pues afectaría solamente a posesiones que todavía no le pertenecían. La idea fue apoyada por el fiscal Campomanes, quien publicó en 1765 su Tratado de la regalía de amortización que, según Tomás y Valiente, no es más que una ampliación del alegato de Francisco Carrasco. ${ }^{4}$

Este programa buscaba restringir las futuras adquisiciones de bienes inmuebles por parte de la Iglesia, pero sin ánimo de despojarla de su patrimonio. El proyecto de ley, votado en el Consejo Real en junio de 1766, fue derrotado. Parece que los votos favorables fueron los de individuos que, posteriormente, formaron parte del Consejo Extraordinario $0^{5}$, un órgano encargado de elaborar la "pesquisa secreta" para la averiguación de los responsables de los motines de 1766, que después se ocuparía de la gestión de la expulsión de la Compañía de Jesús de los dominios hispanos.

\section{EL CONSEJO EXTRAORDINARIO}

Las revueltas de 1766 causaron un profundo impacto en el ánimo de Carlos III, que era de la opinión de que después de unos hechos tan graves, sus promotores no debían quedar impunes. Mediante el Real Decreto de 21 de abril de 1766 mandaba al presidente del Consejo de Castilla, el conde de Aranda, ${ }^{6}$ junto con un ministro que él designase ${ }^{7}$ y el fiscal del mismo Consejo, Pedro Rodríguez Campomanes, que llevasen a cabo una investigación secreta, la llamada "pesquisa reservada", para averiguar las causas y las responsabilidades de los levantamientos, y evitar así que tales hechos pudieran reproducirse en el futuro. ${ }^{8}$

4 Tomás y Valiente, Francisco 1977. El marco político de la desamortización en España: 23-26, Barcelona: Ariel.

5 Ídem.

6 Pedro Pablo Abarca de Bolea, capitán general de Castilla la Nueva, había sido nombrado presidente del Consejo de Castilla diez días antes. Corona, Carlos E. 1975. "Sobre el Conde de Aranda y sobre la expulsión de los jesuitas", en Homenaje al Dr. D. Juan Reglá, vol. 2: 79-106, Valencia: Universidad de Valencia, Facultad de Filosofía y Letras.

${ }^{7}$ La elección, efectuada el día 26 de abril de 1766, recayó en el ministro del Consejo de Castilla Miguel María de Nava.

${ }^{8}$ Archivo General de Simancas [en adelante AGS], Gracia y Justicia, leg. 1009. Sobre la pesquisa reservada véase: Egido, Teófanes 1976. "Motines de España y proceso contra los jesuitas". Estudio Agustiniano 11: 219-260; Egido, 
Desde el principio se consideró que no debía tratarse este delicado asunto en el Consejo pleno de Castilla, pues debido a su elevado número de miembros, sería difícil la toma de decisiones y sería mucho más complicado el mantenimiento del secretismo necesario. Se creyó más adecuado, por tanto, constituir una sala extraordinaria que, dotada de unos poderes excepcionales e independientes de cualquier otro organismo público, se reuniese cuando fuese necesario, sin despertar sospechas, en principio en la propia residencia del conde de Aranda. ${ }^{9}$

Pronto se observó que, para desarrollar correctamente la investigación, era necesario el aumento del número de sus miembros. Por ello, el día 8 de junio se propuso la elección de Pedro Ric ${ }^{10}$ y de Luis del Valle Salazar, y se eligió a José Payo Sanz en calidad de escribano honorario de Cámara. Estos nombramientos no fueron los únicos, ya que unos meses después, el día 19 de octubre, se expidió un real decreto con tres nuevas incorporaciones: el conde de Villanueva, decano del Consejo, Andrés de Maraver y Vera, y Bernardo Caballero. ${ }^{11}$

Se encargó al conde de Aranda que todos los miembros del tribunal realizaran un juramento por el que se comprometieran a mantener

"un profundo secreto, así de los nombres de los testigos y piezas reservadas acumuladas al proceso, como del asunto sobre que han de tratar, y de lo que ocurriere y se acordare, de manera que por ninguna vía den a entender por escrito o de palabra el objeto de su concurrencia, examen y deliberaciones". ${ }^{12}$

Teófanes y Pinedo, Isidoro 1994. Las causas "gravísimas" y secretas de la expulsión de los jesuitas por Carlos III: 64-95, Madrid: Fundación Universitaria Española; Guasti, Niccolò 2006. Lotta política e riforme all'inizio del regno di Carlo III, Firenze: Alinea.

${ }^{9}$ Archivo Campomanes [en adelante AC] 45/3; Consejo Extraordinario; Madrid 29 de enero de 1767.

10 Pedro Ric y Egea era consejero de Castilla y de la Inquisición en la primera parte de la década de 1760. Castro, Concepción de 1996. Campomanes. Estado y reformismo ilustrado: 148, nota 55 Madrid: Alianza Editorial.

11 AGS, Gracia y Justicia, leg. 1009; Carlos III al conde de Aranda, presidente del Consejo; San Lorenzo, 19 de octubre de 1766.

12 AGS, Gracia y Justicia, leg. 1009; Carlos III al conde de Aranda; San Lorenzo, 31 de octubre de 1766. 
La ruptura de este compromiso sería considerada un delito de Estado cometido por personas en las que el Rey había depositado su mayor confianza.

El Consejo Extraordinario, así configurado, se modificó con la sustitución del conde de Villanueva, cuya vejez y problemas de salud le impedían asistir a las reuniones. Se eligió entonces al vicedecano del Consejo, Pedro Colón de Larreategui, ${ }^{13}$ quedando el conde de Villanueva obligado a acudir a las juntas, aunque parece que no lo hacía. ${ }^{14}$

La elección de los ministros integrantes del Consejo Extraordinario no fue al azar. Se escogió a personas de ideología tomista ${ }^{15}$ que, además, eran afines a la manera de pensar del fiscal. ${ }^{16}$

El resultado de la "pesquisa secreta" fue la aparición del Dictamen fiscal de Campomanes ${ }^{17}$ en diciembre de 1766. En sus 746 puntos, el fiscal asturiano pretendió influir tanto en la opinión de Carlos III como en la del resto de los miembros del Consejo Extraordinario.

El dictamen recurría repetidamente al ejemplo de las monarquías portuguesa y francesa, de donde los jesuitas fueron expulsados y suprimidos en 1759 y 1764 respectivamente. Se subrayaba el cuarto voto de obediencia al Papa para demostrar que los ignacianos eran una corporación independiente del Estado, a las órdenes de un poder político extranjero, insinuando frecuentes desvíos de capital hacia Roma en

${ }^{13}$ Cuyo nombramiento tuvo lugar el día 29 de diciembre de 1766. AGS, Gracia y Justicia, leg. 1009; Carlos III al conde de Aranda; Palacio, 29 de diciembre de 1766.

${ }^{14}$ Egido, Teófanes y Pinedo, Isidoro 1994: 33.

15 Irles Vicente, María del Carmen 1997. "Tomismo y jesuitismo en los tribunales españoles en vísperas de la expulsión de la Compañía", en E. Giménez (ed.), Expulsión y exilio de los jesuitas españoles: 41-66. Alicante: Publicaciones de la Universidad de Alicante; Egido, Teófanes y Pinedo, Isidoro 1994: 36-37.

16 Tomás y Valiente afirmaba que los miembros del Consejo Extraordinario fueron los individuos que votaron favorablemente el plan que habían propuesto los fiscales Francisco Carrasco y Pedro Rodríguez Campomanes para limitar las futuras adquisiciones de bienes inmuebles por parte de la Iglesia que, finalmente, no obtuvo todo el apoyo necesario para llevarse a cabo. Tomás y Valiente, Francisco 1977: 23-24.

17 Rodríguez de Campomanes, Pedro 1977. Dictamen fiscal de la expulsión de los jesuitas de España (1766-1767). Edición, introducción y notas de Jorge Cejudo y Teófanes Egido, Madrid: Fundación Universitaria Española. 
perjuicio de la monarquía. Campomanes insistió, asimismo, en atribuir ideas regicidas y tiranicidas a los miembros de la Orden. Tuvo esto una enorme influencia sobre Carlos III, que todavía tenía fresco en su memoria el recuerdo de las revueltas de 1766. Con todo ello, el Dictamen fiscal se convirtió en un documento determinante para que el monarca se decidiese a llevar a cabo la expulsión de la Compañía de Jesús como una medida imprescindible para garantizar la quietud de sus vasallos y la subordinación de su pueblo.

El monarca Borbón, intranquilo, quedó totalmente convencido de los inminentes peligros a los que se encontraba expuesto su reino, según le indicaban su fiscal y su Consejo. La acción a desarrollar debía caracterizarse por su secretismo y utilizar el factor sorpresa para impedir cualquier oposición. El resultado fue la pragmática sanción de 2 de abril de 1767, en la que el soberano manifestaba su obligación de mantener sus reinos en paz y tranquilidad, por lo que ordenaba, en base a unos motivos que prefería reservarse para si $^{18}$, lo siguiente:

"Hé venido en mandar estrañar de todos mis Dominios de España, é Islas Filipinas, y demás adjacentes á los Regulares de la Compañia [...] y que se ocupen todas las temporalidades de la Compañía en mis Dominios". ${ }^{19}$

A pesar de creer que las razones que motivaban esta providencia estaban justificadas sobradamente, el Consejo consideraba que la medida debía revestirse, desde el primer momento, de un aire de humanidad y justicia, a fin de que fuese una disposición aceptada por todos. Se quiso, por tanto, mostrar en todo momento la voluntad del monarca de tratar respetuosamente a los jesuitas en la expulsión y, de igual forma, se insistió en que sus propiedades se aplicarían para el desarrollo de obras beneficiosas para el Estado. Muestra de ese talante compasivo del rey fue la concesión de una pensión vitalicia de cien pesos para los sacerdotes y noventa para los legos, que debía ser pagada anualmente. Este subsidio trataba de evitar cualquier reproche

${ }^{18}$ El Consejo Extraordinario consideró que Carlos III debía utilizar esta frase, sin introducirse en valoraciones referentes al instituto de la Compañía o a las costumbres de los jesuitas.

19 "Pragmatica Sancion de SM, en fuerza de Ley, para el estrañamiento de estos Reynos á los Regulares de la Compañia, ocupacion de sus Temporalidades, y prohibicion de su restablecimiento en tiempo alguno, con las demas precauciones que expresa", CGP, parte primera, XIII: 28-34. 
económico por parte del Pontífice, que había asumido los gastos necesarios de la manutención de los jesuitas portugueses, quienes no recibieron ningún tipo de ayuda económica de parte del monarca portugués José I, a pesar de su reducido número en comparación con los hispanos. $^{20}$

Precisamente, este elemento solidario de la concesión de una paga anual, se revistió de un marcado carácter político, pues la pensión se convirtió en uno de los instrumentos más eficaces de control de los exiliados, ya que se les podía amenazar con su pérdida si actuaban en contra de los intereses reales, o por el contrario, se les podía incentivar, doblando o triplicando las cantidades establecidas, en el caso de que realizasen labores útiles para los intereses de la monarquía. ${ }^{21}$

No finalizó la misión del Consejo Extraordinario una vez expatriada la Compañía de Jesús, pues había sido creado, además, para hallar a los responsables de los motines del año anterior. El 7 de septiembre de 1767 se incrementó su número de consejeros, con el objeto de poder atender correctamente la correspondencia de las Indias. Para ello se eligió a dos personas que, además de su talento y méritos, habían estado en América: Pedro León y Escandón, y el marqués de San Juan de Tasó. ${ }^{22}$

Dos meses después de esta incorporación, se creyó oportuno que el Consejo Extraordinario contase con la participación de cinco destacadas personalidades eclesiásticas, cuya misión sería la de garantizar los intereses de la Iglesia en el momento en el que se decidiese el nuevo uso que debía darse a las propiedades de la Compañía de Jesús. Éstas tendrían que ser destinadas para el cumplimiento de ciertos fines beneficiosos para el Estado, aunque se insistió en todo momento en que las nuevas aplicaciones se basarían en el respeto de determinados criterios piadosos y siempre tendrían presente las intenciones de sus fundadores. Los prelados elegidos fueron los arzobispos de Burgos y Zaragoza, y los obispos de Tarazona,

${ }^{20}$ La Asistencia portuguesa la componían, aproximadamente, unos mil cuatrocientos ochenta miembros.

21 Fernández Arrillaga, Inmaculada 2007. "El exilio de los jesuitas Andaluces", en J. Morales y A. Galán (eds.), La Compañía de Jesús en España: otra mirada: 107-128. Madrid: Grupo Anaya; Fernández Arrillaga, Inmaculada 2004. El destierro de los jesuitas castellanos (1767-1815): 54 y ss. Valladolid: Junta de Castilla y León.

22 AGS, Gracia y Justicia, leg. 1009; Aranda a Roda; Madrid, 7 de septiembre de 1767. 
Albarracín y Orihuela. ${ }^{23}$ De esta forma, el Consejo Extraordinario quedó configurado como se indica a continuación:

\begin{tabular}{|c|}
\hline COMPOSICIÓN DEL CONSEJO EXTRAORDINARIO A FINALES DE 1767 \\
\hline Presidente: \\
Conde de Aranda \\
Consejeros seculares: \\
Pedro Colón de Larreategui \\
Miguel María de Nava \\
Andrés de Maraver y Vera \\
Luis de Valle Salazar \\
Pedro León y Escandón \\
Bernardo Caballero \\
Marqués de San Juan de Tasó \\
Felipe Codallos \\
Consejeros eclesiásticos: \\
José Javier Rodríguez de Arellano, arzobispo de \\
Burgos \\
Juan Saenz de Buruaga, arzobispo de Zaragoza \\
José Tormo y Juliá, obispo de Orihuela \\
José de Molina, obispo de Albarracín \\
José de Laplana y Castillón, obispo de Tarazona \\
Escribano de Cámara: \\
José Payo Sanz \\
Fiscales: \\
Pedro Rodríguez Campomanes (Corona de \\
Castilla) \\
José Moñino Redondo (Corona de Aragón) \\
\hline
\end{tabular}

Pese a sus objetivos iniciales, el Consejo Extraordinario quedó configurado como la institución más elevada, por debajo de la figura del monarca, con competencias en todos los asuntos relacionados con las

${ }^{23}$ AGS, Gracia y Justicia, leg. 1009; comunicación dirigida al conde de Aranda; San Lorenzo, 9 de noviembre de 1767. Con anterioridad, el día 2 de octubre de 1767 se había nombrado a Felipe Codallos como miembro del Consejo para sustituir al difunto Pedro Ric y Egea. AGS, Gracia y Justicia, leg. 1009; comunicación dirigida al conde de Aranda; San Lorenzo, 2 de octubre de 1767. 
temporalidades de los jesuitas. Con el paso del tiempo y paulatinamente fue perdiendo poder hasta su desaparición en $1792 .^{24}$

\section{DIRECCIÓN, CONTADURÍA Y DEPOSITARÍA GENERAL DE TEMPORALIDADES}

La Dirección, contaduría y depositaría general de temporalidades fue también conocida como la Depositaría general. Se estableció el día 10 de mayo de 1767 en la oficina de la Tesorería General y con personal de la misma. Fue éste un organismo que no debe confundirse con la Contaduría general, de cuyo funcionamiento nos ocuparemos en su apartado correspondiente.

Una vez expulsados los jesuitas, los esfuerzos de las autoridades se centraron en garantizar la seguridad del conjunto de sus caudales, sin que hubiese que crear una tesorería particular para ello. Debía, por tanto, configurarse un depósito en el que confluyesen los capitales encontrados en los colegios en el momento del destierro, las cantidades que fuesen pagando los deudores de los jesuitas y aquellas que generase la propia administración de sus temporalidades.

De esta forma, la Depositaría general quedó constituida como un fondo diferenciado de la Real Hacienda y destinado a pagar los gastos derivados de la operación de extrañamiento. Se trataba de una suma nada despreciable, ya que incluyó el coste del transporte de los jesuitas hacia los puertos de embarque, escoltados en todo momento por el ejército, el pago de la tripulación de los navíos en los que fueron trasladados hasta el puerto romano de Civitavecchia, ${ }^{25}$ la remuneración a los comisarios reales... Fue también un depósito para satisfacer las pensiones concedidas a los jesuitas, y un lugar del que obtener los fondos para afrontar las deudas contraídas con los diferentes acreedores. Los movimientos pecuniarios de este fondo quedaban

${ }^{24}$ Martínez Tornero, Carlos A. 2010. Carlos III y los bienes de los jesuitas. La gestión de las temporalidades por la monarquía borbónica (17671815), Alicante: Publicaciones de la Universidad de Alicante.

${ }^{25}$ Para una mayor información sobre este tema véase: Giménez López, Enrique 1997. "El ejército y la Marina en la expulsión de los jesuitas de España", en E. Giménez (ed.), Expulsión y exilio de los jesuitas españoles: 67114. Alicante: Publicaciones de la Universidad de Alicante; Fernández Arrillaga, Inmaculada 2006. "El extrañamiento de los jesuitas valencianos", en E. Giménez (ed.), De cosas y hombres de nación valenciana. Doce estudios en homenaje al Dr. Antonio Mestre Sanchís: 341-375, Alicante: Publicaciones de la Universidad de Alicante. 
controlados en todo momento, pues era obligatorio contar con una orden formal del Consejo que autorizase cualquier desembolso.

La Depositaría general la dirigió el tesorero general Cosme Bermúdez de Castro, a quien se le encargó la tarea de seleccionar a los oficiales mejor preparados de la Tesorería General, en calidad de individuos experimentados en la custodia, cobranza y desembolso de caudales. Se le encomendó también la labor de determinar el emplazamiento más adecuado, dentro de la Tesorería, para almacenar sin riesgo el patrimonio confiscado.

Con ese objeto se construyó una habitación contigua a la caja principal de la Tesorería General, de manera que ambas dependencias quedaron completamente separadas. La nueva estancia permanecería cerrada por una puerta de tres cerrojos, cuyas llaves quedaron repartidas entre los tres oficiales principales que debían integrar la Depositaría: el tesorero general, el contador de intervención y el depositario general.

Los tres debían concurrir con su llave a todos los ingresos y pagos expedidos en virtud de libramientos formales del Consejo, y formar el llamado libro maestro del depósito, un compendio en el que debían constar formalmente todas las entradas y salidas de caudales. Los tres oficiales de la Depositaría tendrían que tener noticia de cualquier movimiento del dinero y, a su vez, era preciso que quedase constancia escrita de tales operaciones.

Cada uno de ellos tenía unas responsabilidades específicas y estaba acompañado de unos ayudantes. Atendiendo a sus funciones, se estableció una jerarquía entre ellos, de la que daremos cuenta a continuación. ${ }^{26}$

\section{El tesorero general}

Se ocupaba de la recolección de los caudales, proveyendo las órdenes oportunas para que el capital se depositase en las tesorerías de ejército si fuese conveniente. Proponía al Consejo a los empleados de la Tesorería General más adecuados, pues era el único de los tres

26 Martínez Tornero, Carlos A. 2008. "Las temporalidades jesuitas. Aproximación al funcionamiento administrativo después de la expulsión de la Compañía de Jesús en 1767", en Esteban de Terreros y Pando: vizcaíno, polígrafo y jesuita. III Centenario: 1707-2007: 537-562, Bilbao: Deusto publicaciones. 
miembros señalados capacitado para comunicarse con el Consejo Extraordinario. Por último, se ocupaba de que los subalternos y dependientes desempeñasen sus funciones con exactitud.

\section{El contador de intervención}

Examinaba las partidas del tesorero general, controlando las cantidades percibidas por los tesoreros de ejército procedentes de subdelegados o depositarios particulares. Registraba los recibos de entradas de capital, expidiendo las cartas de pago formales que debía dar el depositario a favor de las personas correspondientes. Finalmente, formaba cada cuatro meses la nómina de los subalternos, pasándola al tesorero general para que la remitiese al Consejo. En caso de ausencia era sustituido por el contador de la Tesorería General o, en su defecto, por dos oficiales mayores de los negociados de Hacienda y Guerra.

\section{El depositario general}

Era auxiliado por un ayudante que se encontraba a sus órdenes para el peso y recibo de los caudales, y para la satisfacción de los libramientos y abonos del Consejo, siguiendo el mismo método que se utilizaba con el dinero de la Real Hacienda. Llevaba una cuenta independiente de los ingresos e, igualmente, expedía recibos a los tesoreros de ejército, y cartas de pago formales a favor de las personas que hiciesen entregas de capital. Por último, estaba encargado de confeccionar una relación, al final de cada mes y cada año, o cuando el Consejo lo solicitase, para verificar las entradas y salidas de capital y las existencias de la depositaría. ${ }^{27}$ siguiente:

La primera plantilla de los empleados de este organismo fue la

${ }^{27}$ Más información sobre estos cargos en Martínez Tornero, Carlos A. 2010. 
EMPLEADOS DE LA DIRECCIÓN, CONTADURÍA Y DEPOSITARÍA GENERAL EN $1767^{28}$

\section{Dirección}

Contaduría

Tesorero general: Cosme Bermúdez de Castro

Oficial primero: Agustín de Lasarte

Oficial segundo: Pedro Martínez Valenzuela

Escribano: Ignacio Balbín

Contador de intervención: Juan del Corro

Oficial primero: Estanislao del Corro

Oficial segundo: Ramón de Montserrat

Depositaría

Escribano: José de Ocáriz

Depositario general: Francisco de Arcaya

Ayuda de caja: Marcos Antonio López

Oficial primero: Juan Francisco de Juanicotena

Escribano: Ignacio López Corona

Escribano: Juan Treviño

Portería

Portero: José Ruperto de Sierra

Con el paso del tiempo se produjeron cambios en esta primera plantilla de empleados, hasta que, en el año 1809, se decidió que los caudales que pertenecieron a los jesuitas debían pasar a formar parte de los llamados bienes nacionales, con el objetivo de hacer frente a la enorme deuda pública. A partir de entonces, las temporalidades de los jesuitas dejaron de ser tratadas con exclusividad, para ser integradas en un depósito en el que confluyeron otro tipo de caudales de diferente naturaleza, con el objetivo de disminuir el déficit que atravesaban las finanzas públicas, como veremos más adelante.

\section{CONTADURÍA GENERAL DE TEMPORALIDADES}

La Contaduría general de temporalidades se estableció en el Colegio Imperial de Madrid y funcionó desde el día 27 de octubre de 1767. La Dirección, contaduría y depositaría general de temporalidades, por el contrario, como hemos visto, apareció el día 10 de mayo de 1767 y 14.

${ }^{28}$ Fuente: AGS, Dirección General del Tesoro, Inventario 27, legs. 3 y 
se ubicaba en la Tesorería General, contando, además, con oficiales de la misma institución. Es necesario reiterar esta diferencia principal para evitar confusiones. Hasta ahora, cuando se ha tratado de explicar el funcionamiento de la administración de las propiedades ocupadas a los jesuitas, no se tuvo clara esta distinción, dando lugar a confusiones e incoherencias. $^{29}$

Al frente de la Contaduría general se encontraba Juan Antonio Archimbaud y Solano, contador general de temporalidades. Este organismo estaba relacionado con la administración y gestión de las cuentas y demás aspectos económicos generados a raíz de la expulsión de la Compañía de Jesús. Era una oficina que tenía que rendir cuenta al Consejo de los caudales que poseyeron los jesuitas, informando, igualmente, de las inversiones que se realizasen con ellos. Para ese fin, elaboraba estadillos y resúmenes sobre la liquidez de las temporalidades, las fincas vendidas y los jesuitas con pensión, para lo cual era preciso registrar de manera conveniente los fallecimientos que se fueran produciendo. Finalmente, debía ocuparse de supervisar el cumplimiento de las cargas y el pago de los gastos a los que tuviesen que hacer frente las propiedades, formando un libro becerro, es decir, un compendio en el que constasen las fundaciones de los colegios y sus obligaciones, para asegurar la observancia de sus cargas y gravámenes. En definitiva, se trataba de una labor completamente necesaria para poder gestionar correctamente los capitales de los jesuitas.

29 El trabajo de Mateos, F. 1967. "Notas Históricas sobre el antiguamente llamado 'Archivo de las temporalidades' de jesuitas", en A. Guglieri Navarro, Documentos de la Compañía de Jesús en el Archivo Histórico Nacional, Madrid: Razón y Fe, indica que la Contaduría general apareció en 1783 como una institución disgregada de la Dirección, contaduría y depositaría general de temporalidades debido a que fue adquiriendo personalidad dentro de la misma [p. XXXII]. De igual forma afirma que la Depositaría general se convirtió en la Dirección general de temporalidades [p. XXVI]. Esta confusión ha sido heredada por aquellos que se han basado en este trabajo para tratar de explicar esta cuestión. Por otra parte, ha habido autores que han eludido el problema al explicar el funcionamiento de la Depositaría general sin hacer mención a la Contaduría general, considerando que se trataba del mismo organismo. Véanse a este respecto: López Martínez, Antonio Luis 1988: "El patrimonio económico de los jesuitas en el reino de Sevilla y su liquidación en tiempos de Carlos III". Archivo Hispalense 217: 35-60; López Martínez, Antonio Luis 1999. "El patrimonio rústico de los jesuitas en España. Una aproximación". Hispania 203: 925-954; García Trobat, Pilar 1992. La expulsión de los jesuitas, Valencia: Generalitat Valenciana; García Trobat, Pilar 1999. El patrimonio de los jesuitas en Valencia y su desamortización, Valencia: Bèrnia Edicions. 
De igual forma, la Contaduría general trató de llevar a cabo una tarea muy ambiciosa: la de elaborar un informe general con el estado de los bienes y rentas de cada colegio, el cumplimiento de sus cargas, la aplicación de sus casas e iglesias y las ventas realizadas. Esta tarea pasó después a la Dirección general de temporalidades.

La composición de este organismo la ofrecemos en el cuadro que incluimos a continuación:

EMPLEADOS DE LA CONTADURÍA GENERAL ${ }^{30}$

\section{Oficiales}

Francisco Antonio de San Martín

Agustín de Irusta

Francisco Antonio Cosío

Tomás Payés y Durán

\section{Escribanos}

Francisco González de Tejada

Diego Fernández de Alderete

Casimiro de Guinea

Manuel de Abaitua

Portero

Manuel Zorrilla

\section{LAS JUNTAS PARA LA VENTA DE LOS BIENES}

El Consejo Extraordinario de 16 de octubre de 1767 planteó la conveniencia de ordenar la venta de las propiedades de la Compañía de Jesús, pues tras la marcha de los religiosos sus inmuebles comenzarían a deteriorarse inevitablemente, y necesitarían ciertas reparaciones. Además, se consideraba que su arrendamiento sería perjudicial para los propios bienes y sólo serviría para enriquecer a los que se encargasen de ellos.

${ }^{30}$ Los empleados que figuran en este cuadro son los miembros que integraban la Contaduría general en 1770 , si bien creemos que la primera plantilla de esta institución no debía diferir mucho de estos datos. Fuente: AGS, Dirección General del Tesoro, Inventario 27. 
Sin embargo, no fue hasta 1769 cuando se decidió que las posesiones de los jesuitas debían subastarse públicamente. Se creyó entonces que la comercialización del patrimonio acabaría con todas las preocupaciones derivadas de su administración, como el control necesario para que los arrendatarios pagasen puntualmente o la vigilancia del cumplimiento de las cargas que tenían aparejadas los bienes. Pero además de ello, la venta del patrimonio sería doblemente conveniente porque al recaer los inmuebles en manos de seglares quedarían sujetos al pago de impuestos. Para las ventas y otros aspectos relacionados con ellas nacieron las juntas municipales y provinciales en la península.

\section{Las juntas municipales}

Debía establecerse una junta municipal en cada una de las ciudades en las que estuvieron establecidos los jesuitas. Estos organismos quedarían integrados por el juez comisionado de cada colegio, un regidor nombrado por el ayuntamiento, los diputados y personero del común y un eclesiástico señalado por el obispo o arzobispo de la diócesis.

Entre sus labores se encontraban las de revisar los inventarios en los que se indicaban los bienes que los jesuitas poseyeron en cada colegio, examinar las tasaciones efectuadas sobre las propiedades jesuitas y valorar aquellas que no hubiesen sido apreciadas, fijar carteles anunciando la venta general de bienes, admitir las pujas realizadas, depositar en arcas reales el importe de las ventas y cumplir con los gravámenes existentes sobre los bienes mientras éstos no se vendiesen.

\section{Las juntas provinciales}

Nacieron al ser imposible que el Consejo examinara todas las operaciones mercantiles. Con ellas, podrían evaluarse las ventas atendiendo a las características de cada provincia. Su composición era diversa dependiendo del lugar en el que se encontrasen establecidas. ${ }^{31}$

A grandes rasgos, las juntas provinciales tenían un papel de supervisión sobre las municipales. Debían estimularlas para la ejecución de las tasaciones, distribuir por todo el reino los estadillos elaborados por las juntas municipales para que saliesen postores, informar al Consejo

31 Existían diferencias entre las localidades en las que existía una Chancillería o Audiencia Real y las que no, y ciertas particularidades locales en las de Álava, Vizcaya, Guipúzcoa, Madrid, Guadalajara, Toledo e Ibiza. Véase a este respecto Martínez Tornero, Carlos A. 2008 y Martínez Tornero, Carlos A. 2010. 
sobre aquellos casos en los que hubiese dudas y dar órdenes a las municipales para la admisión de los remates de las subastas en las pujas más elevadas, en caso de que no encontrasen ninguna objeción.

Volviendo a la cuestión de las ventas, el 8 de noviembre de 1769 se expidió una real cédula que establecía un plazo de cuarenta días para que se comercializasen los bienes, ya que las ventas no caminaban "con la brevedad que debe desearse". Debemos señalar que éste fue un cálculo demasiado optimista y que resultó a todas luces irrealizable, pues el negocio de las temporalidades no finalizaría hasta muchos años después. No obstante, al principio se pensó que la lentitud de las ventas podía deberse a la existencia de rumores contra la estabilidad y permanencia de los contratos. Por ello, el rey declaró en la real cédula citada que una vez que los contratos fuesen aprobados por las juntas

"ninguno de mis Tribunales, Junta, ni Juez, de qualquiera calidad que sea, pueda admitir en tiempo alguno demanda sobre nulidad, rescision, tantéo, suplemento, restitucion, ni otra instancia alguna, que no sea sobre el cumplimiento de dichos contratos, y sus condiciones, a cuyo efecto aseguro por mi fe y palabra Real esta misma permanencia y perpetuidad". 32

El empeño por asegurar la permanencia de las transacciones hace suponer la existencia de alguna inseguridad entre los posibles interesados sobre el futuro de sus compras. Como indican los profesores Giménez López y Alberola Romá, estas dudas podrían ser el fruto de los rumores lanzados por los enemigos de la expulsión sobre la ilegalidad de esos contratos o de las habladurías que presagiaban la pronta restitución de la Compañía de Jesús. ${ }^{33}$

32 "Real Cedula a consulta de los Señores del Consejo, en el Extraordinario, por la qual S.M. prescribe á las Juntas Provinciales y Municipales el último término para la venta de Bienes, pertenecientes á las Temporalidades de los Regulares de la Compañia, en cumplimiento de la anterior de veinte y siete de Marzo de este año; y asegura la perpetuidad de estos contratos baxo de la fé y palabra Real", en CGP, parte tercera, IX: 123128.

33 Alberola, Armando y Giménez, Enrique 1982. "Las temporalidades de la Compañía de Jesús en Alicante". Revista de Historia Moderna. Anales de la Universidad de Alicante 2: 167-210. 
Lo cierto es que el mayor volumen de venta se produjo entre 1769 y 1774, concentrándose sobre todo en los años de 1770 y 1771 . Yun Casalilla justifica esta rapidez en unos años de coyuntura agrícola positiva, en los que se adquirieron las mejores tierras. Las operaciones comerciales continuaron siendo destacables hasta el año 1784, para disminuir a continuación, de forma que los índices más bajos se registraron a finales de siglo. La cota mínima, antes de concluir la centuria, fue durante los años 1795 y 1797 debido, probablemente, a la mala coyuntura económica del país. ${ }^{34}$

Parece que los principales beneficiarios con las enajenaciones fueron los estamentos de la nobleza y la burguesía urbana, teniendo un papel poco destacado otros grupos, como el pequeño campesinado. Los burgueses participaron de manera más activa. Nos referimos a los grandes comerciantes, los grandes labradores y los funcionarios de las localidades en las que se vendieron las propiedades de los jesuitas y de las de fuera. ${ }^{35}$

\section{Las juntas en Indias}

La venta de las propiedades jesuitas en las Indias tenía que ajustarse a las mismas reglas que en la península, en la medida de lo posible, mediante una fluida comunicación con el Consejo de Indias. Factores como la distancia con la metrópoli y las características propias de aquellas tierras motivaron la expedición de la Real Cédula de 9 de julio de 1769, que reglamentaba la creación de juntas superiores y subalternas para los dominios ultramarinos. ${ }^{36}$

\section{Las Juntas superiores}

La Real Cédula de 9 de julio de 1769 establecía la necesidad de crear diez juntas superiores en las Indias, independientes unas de otras, para elaborar consultas en las que se propusiese el mejor destino que

34 Yun Casalilla, Bartolomé 1986. "La venta de los bienes de las temporalidades de la Compañía de Jesús. Una visión general y el caso de Valladolid (1767-1808)", en Desamortización y hacienda pública, vol. 1: 293316, Ministerio de Agricultura, Pesca y Alimentación, Secretaría General Técnica; Ministerio de Economía y Hacienda; Instituto de Estudios Fiscales.

${ }^{35}$ López Martínez, Antonio Luis 1999.

36 "Real Cédula de S.M. y Señores del Consejo en el Extraordinario, por la qual se manda establecer en los Dominios Ultramarinos de Indias, é Islas Filipinas Juntas, para proceder á la aplicacion y destino de las Casas, Colegios, Residencias, y Misiones, que fueron de los Regulares de la Compañia, con las reglas prácticas convenientes, resueltas por S.M. á consulta del mismo Tribunal", en CGP, parte tercera, V: 100-120. 
convenía dar a las casas, colegios, residencias y misiones que los jesuitas poseyeron en aquellos territorios.

Estas juntas tenían que estar integradas por el virrey o gobernador, el arzobispo u obispo, el decano de la Real Audiencia u otro ministro de ella, uno de los fiscales y el "protector de indios" en las Audiencias en las que lo había, para promover el interés y el bien espiritual de éstos en las aplicaciones.

Un aspecto fundamental es que este tipo de juntas carecía de autoridad para llevar a cabo aplicaciones, fundaciones 0 establecimientos, por tratarse de una materia reservada a la regalía. Se limitaba a proponer los que a su juicio eran los mejores destinos para los edificios exentos de los procesos de venta y llevar a cabo la enajenación del patrimonio que debía comercializarse. Sin embargo, sí tenían atribuciones para resolver aquellos conflictos poco trascendentes que pudieran surgir sobre su modo de obrar, a fin de evitar retrasos y pleitos innecesarios.

\section{Juntas subalternas}

Con el objeto de facilitar su labor, las juntas superiores recibieron la facultad de poder erigir unas juntas subalternas que sirviesen para auxiliarles en sus funciones, ayudándoles con la recogida de información y otros aspectos. Únicamente se les previno para que no multiplicasen excesivamente este tipo de juntas que, al igual que en los casos precedentes, debían quedar configuradas con diferentes miembros de la autoridad eclesiástica y civil.

\section{LA DIRECCIÓN DE TEMPORALIDADES}

Anteriormente hemos hecho referencia a la labor desempeñada por la Contaduría general de temporalidades. Unos años después de su creación tuvo lugar la reestructuración de este organismo, en 1773, con la intención de agilizar los trámites que despachaba, ya que el número de asuntos pendientes era cada vez más elevado. A este respecto se produjo el nombramiento de cuatro oficiales para ocuparse del despacho de los asuntos pertenecientes a las cuatro provincias jesuitas de la metrópoli (Aragón, Bética, Castilla y Toledo) y tres empleados para 
desempeñar la misma función con los asuntos de Indias. No obstante, la nueva organización no fue suficiente, por lo que diez años después, en 1783, se configuró un nuevo organismo en sustitución de la Contaduría general: la Dirección general de temporalidades.

En efecto, la Real Cédula de 14 de noviembre de 1783 mandaba la creación de la Dirección general de temporalidades en sustitución de la anterior Contaduría general. ${ }^{37}$ Se trataba de un paso muy importante en la administración de los bienes que pertenecieron a la Compañía de Jesús, al establecer una clara distinción entre las temporalidades de la metrópoli y las de las Indias, mandando que, desde ese momento, las propiedades que los jesuitas poseyeron en los dominios ultramarinos quedasen a cargo del Secretario de Estado y del despacho universal de las Indias, del Consejo de Indias y de las Audiencias y tribunales de su jurisdicción.

Esta medida se tomaba para evitar los inconvenientes existentes hasta ese momento, como los atrasos en la cobranza de las ganancias o la confusión y falta de información que había en la metrópoli respecto a aquellas temporalidades, lo cual constituía un motivo de demora en la resolución de todos los asuntos relacionados con esa materia. Eso sí, se especificaba que habría que tener presentes las reglas que se diesen para la península, en la medida en que éstas fuesen adaptables para aquellos territorios.

La reglamentación dada establecía que las temporalidades de las Indias tenían que efectuar un pago en la Depositaría general por valor de 11.255.380 reales, ya que se consideraba que ésa era la suma a la que ascendía el conjunto de los gastos que las temporalidades metropolitanas habían suplido para cubrir todos los desembolsos precisos relativos a los jesuitas de aquellos dominios entre 1767 y 1782 . Igualmente, desde entonces deberían enviar también a la Depositaría, anualmente y por adelantado, 2.500 .000 reales de vellón con los que cubrir el pago de la pensión y demás gastos imprescindibles que generasen los jesuitas indianos.

Por otra parte, en lo que se refiere a los dominios peninsulares, la citada real cédula ordenaba la creación de una "Dirección de las temporalidades de España e islas adyacentes", que se encontraría a cargo del contador, Juan Antonio Archimbaud, y su oficina, hasta que se formase un reglamento conveniente. Con ello, se pretendía liberar al

${ }^{37}$ Esta real cédula se puede consultar en Pérez y López, Antonio Javier 1797. Teatro de la Legislación universal de España e Indias: t. XXVII: 73-80, Madrid; y en la CGP, parte quinta, XXIII: 45-55. 
Consejo Extraordinario de ese tipo de atenciones, pues dicho tribunal había mostrado su incapacidad para llevarlas a cabo con el debido cuidado y con la premura necesaria.

La Dirección debía ocuparse de garantizar la recaudación de cualquier tipo de dinero que perteneciese a las temporalidades y hubiese de entregarse en la Depositaría general. Además, el nuevo organismo tendría que completar el trabajo que la Contaduría general había comenzado, sobre la realización del resumen que debía contener el estado de los bienes y rentas de cada colegio, el cumplimiento de sus cargas, la aplicación de sus casas e iglesias, y las ventas realizadas. De esta forma, se obtendría un conocimiento completo de la situación en la que se hallaban las temporalidades en todo momento y se podrían solucionar aquellos aspectos que dificultasen el desarrollo de las aplicaciones acordadas.

EMPLEADOS DE LA DIRECCIÓN DE TEMPORALIDADES

\section{Director}

\section{Contadores}

Juan Antonio Archimbaud y Solano

Laureano Gómez de Ayala

Francisco Antonio de San Martín

\section{Oficiales}

Diego Fernández de Alderete

Tomás Payés y Durán

Justo Lorenzo de Prado

Manuel Antonio Trapero

Juan Herranz

Manuel José Moreno

Basilio Antelo

Manuel Onofre Zapater

\section{Escribanos}

Manuel Martínez

Diego de Castro

Juan José de las Melendreras

Juan Cortes

\section{Porteros}

Manuel Marcos Zorrilla

Valentín Ramón

\section{Barrendero}




\section{Pedro Collado}

\section{LOS SIGNIFICATIVOS CAMBIOS DE 1792 Y 1795}

La Dirección de temporalidades se mantuvo funcionando hasta la expedición del Real Decreto de 25 de marzo de 1792. Alegando que este organismo no cumplió el objetivo con el que había sido creado, Carlos IV se decidió al nombramiento de un hombre con una amplia experiencia en los negocios de las temporalidades, a fin de que esa materia, que tantos años se estaba prolongando, finalizase con la mayor brevedad posible. El elegido fue el gobernador del Consejo, Juan Acedo Rico, conde de la Cañada.

En virtud del real decreto mencionado, el rey le concedía las facultades convenientes para que llevase a cabo todo lo que se había mandado referente a las temporalidades de la península y sus islas desde la expulsión de la Compañía de Jesús. En adelante, la resolución de todo lo que tuviese que ver con ese ramo debería correr por la Secretaría de Gracia y Justicia. ${ }^{38}$

Desde el nombramiento del conde de la Cañada como director de las temporalidades, desapareció la oficina de la Dirección de temporalidades, pero se recuperó la Contaduría general con algunos de los oficiales que compusieron la Dirección y otros nuevos.

A pesar de todos los esfuerzos, el conde de la Cañada no consiguió cumplir con el objetivo que se le encomendó, por lo que tres años después de su designación, ${ }^{39}$ la Real Cédula de 25 de febrero de 1795 nombraba al entonces gobernador del Consejo de Castilla, el obispo de Salamanca, para que continuase la misión que se le encargó a su antecesor. ${ }^{40}$

38 "Real Cédula de SM y señores del Consejo, por la qual se manda cumplir el Decreto inserto, en que se nombra al Conde de la Cañada Gobernador del Consejo, para que dirija y entienda en los negocios de Temporalidades ocupadas á los Regulares de la extinguida Compañia, con todas las facultades amplias y convenientes para que mande llevar á efecto lo resuelto en este asunto. En Madrid, año 1792, en la imprenta de la Viuda e Hijo de Marin"; disponible en la biblioteca de la Universidad de Oviedo.

${ }^{39}$ Seguramente tras su fallecimiento.

40 "Real Cédula de SM y señores del Consejo en que se nombra al obispo de Salamanca gobernador del Consejo, para que dirija y entienda en los 
Todo parece indicar que la labor del obispo de Salamanca tuvo un resultado tan infructuoso en lo que se refiere a la consecución de los objetivos propuestos como su predecesor, por lo que pronto se vio la necesidad de crear nuevos establecimientos que se ocupasen de la administración de estas propiedades. Así, en diciembre de 1797 se mandaba la creación de la Superintendencia general de temporalidades, a cargo de Gaspar Melchor de Jovellanos, y se ordenaba la creación de una Dirección general del mismo ramo, a cuyo frente se puso a Juan Arias de Saavedra. ${ }^{41}$

\section{SUPERINTENDENCIA GENERAL Y DIRECCIÓN GENERAL DE TEMPORALIDADES}

En virtud del Real Decreto de 10 de diciembre de 1797 se creaba la "Superintendencia general de las temporalidades de España, Indias e islas Filipinas", unida e incorporada a la Secretaría de Gracia y Justicia, con lo que, nuevamente, las temporalidades de la metrópoli y las Indias quedaban unidas. A su frente se encontraba Gaspar Melchor de Jovellanos. Esta nueva oficina nacía con la intención de conseguir el cumplimiento de tres objetivos fundamentales:

- En primer lugar, procuraría establecer orden en la administración, recaudación e inversión de los bienes que pertenecieron a la Compañía de Jesús.

- En segundo lugar, trataría de garantizar el cumplimiento de las cargas piadosas que tenían sobre sí este tipo de bienes.

- Finalmente, intentaría reducir gastos en la práctica de las funciones expresadas, estableciéndose que debía seguirse un espíritu de ahorro en la administración de las temporalidades, con la finalidad de evitar despilfarros superfluos.

negocios de temporalidades ocupadas á los Regulares de la extinguida Compañía, con las mismas ámplias y convenientes facultades concedidas á su antecesor. Año 1795. En Madrid, en la imprenta de la viuda é hijo de Marín"; disponible en la biblioteca de la Universidad de Oviedo.

41 "Real Cédula de SM y señores del Consejo en que se manda guardar y cumplir el Real Decreto que se cita, por el qual se crea una Superintendencia general de Temporalidades ocupadas á los Regulares que fuéron de la extinguida Compañía, y tambien una Direccion general de este ramo, que baxo la autoridad de dicha Superintendencia se encargue de su gobierno; en la conformidad que se expresa. Año 1797. En Madrid, en la Imprenta Real", disponible en la biblioteca de la Universidad de Oviedo. 
A la vez que se creaba esta institución, se mandaba el establecimiento de una Dirección general de temporalidades que, bajo la autoridad de dicha Superintendencia, se ocuparía del gobierno de esta materia y de la correspondencia con los tribunales, jueces comisionados y demás empleados en los asuntos de temporalidades. Nuevamente se creaba la figura del director general de temporalidades, que recayó en Juan Arias de Saavedra y Verdugo.

\section{LA INCORPORACIÓN DE LAS TEMPORALIDADES A LA REAL HACIENDA}

La participación española en diferentes contiendas bélicas a finales de siglo, unido a las repetidas emisiones de vales reales, llevaron a la Real Hacienda al borde de la quiebra. En consecuencia, el 19 de septiembre de 1798 Carlos IV firmó cuatro decretos que se convirtieron en el inicio de un largo proceso tendente a la abolición de la propiedad vinculada, como medida para reforzar el crédito público y mantener estable el nivel de ingresos del Erario. ${ }^{42}$ Uno de esos cuatro decretos fue el que ordenaba la venta de las propiedades de la Compañía de Jesús que todavía no se hubiesen comercializado. ${ }^{43}$ Asimismo, se mandaba el traslado de la recién creada Superintendencia general de las temporalidades al Ministerio de Hacienda, que se ocuparía en lo sucesivo de su administración. Los cuatro decretos a los que hemos aludido fueron acompañados por otros tres, de la misma fecha, que tenían como objeto la mejora de la dotación de la caja de amortización, un depósito en el que debería incluirse el producto de las ventas ordenadas en los cuatro primeros decretos.

La incorporación de las temporalidades a la Real Hacienda conllevaba el cese de los expedientes relativos a la aplicación de los bienes de los jesuitas que no hubiesen alcanzado el destino que les confirió el Consejo Extraordinario. Igualmente, quedaban suprimidas todas las juntas superiores, subalternas, provinciales y municipales. En adelante, serían los subdelegados de la Superintendencia general de la Real Hacienda que se encontrasen en las capitales de provincia o en las cabezas de partido los únicos capacitados para intervenir en las ventas,

${ }^{42}$ Azagra, Joaquín 1986. La desamortización de Godoy en Valencia (1799-1807), Valencia: Institució Valenciana d'Estudis i Investigació.

${ }^{43}$ Dicho decreto se puede consultar en Novísima recopilación, libro 1 , título V, ley XXIV: 53-54, y en 1802. Recopilación de todas las providencias respectivas á vales reales expedidas desde 1780, tomo II: 340-344. Madrid, en la imprenta de la viuda e hijo de Marín. 
siguiendo la normativa dada para el resto de los bienes pertenecientes a la Real Hacienda.

Sin embargo, pronto tuvieron lugar una serie de modificaciones. La primera de ellas se produjo tras la expedición de la Real Orden de 8 de julio de 1799. Esta disposición encargaba al tesorero general el gobierno, administración y cobro de los bienes de las temporalidades de la metrópoli y las Indias, el pago de las pensiones a los ex jesuitas, la satisfacción de las cargas piadosas, las enseñanzas y el resto de obligaciones que tuviesen sobre sí. De la misma forma, el tesorero general tendría que favorecer la venta de las fincas y mantener una correspondencia fluida con los jueces comisionados y demás empleados del ramo de temporalidades. Las dudas que le surgiesen las tendría que consultar con la Superintendencia general de la Real Hacienda. ${ }^{44}$

Al año siguiente, se mandaba la aplicación del ramo de temporalidades, junto con el de la venta de los bienes de los colegios mayores de Valladolid (colegio mayor de Santa Cruz), Alcalá (colegio mayor de san Ildefonso) y Salamanca (colegios mayores de San Bartolomé, Cuenca, Oviedo y Santiago), ${ }^{45}$ a la consolidación de vales, por medio de la Real Pragmática de 30 de agosto de 1800.

Precisamente, sería el capítulo noveno de esta real pragmática el que llevaría a la promulgación de la Real Cédula de 21 de octubre de 1800 , que ordenaba la venta de los bienes raíces pertenecientes a las temporalidades de los ex jesuitas, los colegios mayores, la Corona y los vínculos y mayorazgos.

A pesar de todo, pronto tuvo lugar un nuevo cambio, pues el día 9 de febrero de 1801 se ordenó que el tesorero general continuase en la dirección del ramo de temporalidades, debiendo destinar su producto íntegro, una vez cumplidas las cargas, junto con los caudales resultantes de la enajenación de los bienes de mayorazgos, al fondo de

${ }^{44}$ AGS, Dirección General del Tesoro, leg. 6; Miguel Cayetano Soler al tesorero general; 8 de julio de 1799 y 1802. Recopilación de todas las providencias respectivas á vales reales expedidas desde 1780, tomo II: 345347. Madrid, en la imprenta de la viuda e hijo de Marín.

$45 \mathrm{El} 19$ de septiembre de 1798 se había ordenado que el superintendente general de la Real Hacienda procediese a la venta de las fincas de estos colegios mayores para poner su producto en la caja de amortización con el interés del 3\%. Gazeta de Madrid, martes 2 de octubre de 1798. 
consolidación de vales reales. ${ }^{46}$ De esta manera, el tesorero general tendría que hacer un trabajo extra para ocuparse de la recaudación y gobierno de los dos ramos expresados, cuando lo normal era que el Consejo pleno, que se ocupaba de la dirección de dicha caja de consolidación, fuese el que dirigiese la venta de los bienes y destinase los caudales que obtuviese al cumplimiento de las cargas y al pago de los intereses. Si se hacía de esa forma, el tesorero tendría que acudir al Consejo cuando necesitase dinero, pero al dejar en sus manos la dirección de los dos ramos, el tesorero podía disponer de esos fondos directamente, sin rendir cuentas. Este hecho, en palabras de Juan de la Reguera, contribuyó a aumentar los abusos y el desorden de la Tesorería General, en lugar de favorecer las intenciones que se perseguían en el decreto. $^{47}$

\section{LA INCORPORACIÓN DE LAS TEMPORALIDADES A LOS BIENES NACIONALES}

En 1809, bajo dominio francés, se suprimieron las órdenes militares y las comunidades eclesiásticas de regulares ("órdenes regulares, monacales, mendicantes y clericales" y "hermandades y congregaciones conocidas con el nombre de tercera orden"). Todos sus bienes, junto con los de los jesuitas, la Inquisición, los confiscados y los mostrencos y estatales no destinados al servicio público, pasaron a integrar la masa de bienes nacionales desamortizados, que debían venderse en un proceso de subasta pública, con la intención de extinguir la deuda gubernamental antes del 31 de diciembre de $1810 .^{48}$

Con esa misma intención apareció el decreto de 13 de septiembre de 1813, que establecía la venta de una serie de propiedades para llevar a cabo la liquidación de la deuda pública. Estas posesiones se denominaron "bienes nacionales" y fueron: los bienes confiscados a los traidores, los de las temporalidades de los jesuitas, los de la Orden de San Juan de Jerusalén y los de las cuatro órdenes militares; los de conventos y monasterios suprimidos o destruidos durante la guerra, las

46 1802. Recopilación de todas las providencias respectivas á vales reales expedidas desde 1780, tomo II: 348. Madrid, en la imprenta de la viuda e hijo de Marín; y Reguera Valdelomar, Juan 1810. Peticiones sobre reparo de agravios causados en el fatal reinado de Carlos IV. Dirigidas a la Nación española reunida y representada en Cortes generales: 190, Madrid.

${ }^{47}$ Reguera Valdelomar, Juan de la 1810: 190-194.

48 "Para la venta de bienes nacionales para el pago de la deuda pública", en 1810, Prontuario de las leyes y decretos del Rey Nuestro Señor José Napoleón I desde el año de 1805, tomo I: 203-208, Madrid. 
alhajas y fincas llamadas de la Corona y los sitios reales, salvo los que se destinasen a servicio y recreo del rey; y la mitad de los baldíos y realengos. Las fincas se venderían en subastas públicas y debían pagarse en créditos de la deuda nacional. ${ }^{49}$ No obstante, este decreto de 13 de septiembre de 1813 apenas pudo aplicarse debido al inmediato retorno de Fernando VII y del Estado absoluto.

Pese a todo, la suerte de las temporalidades cambiaría a partir del día 7 de agosto de 1814, pues en ese momento, el pontífice Pío VII, por medio de la bula "Sollicitudo omnium ecclesiarum" restablecía oficial y totalmente la Compañía de Jesús.

\section{EL RESTABLECIMIENTO DE LA COMPAÑÍA DE JESÚS}

Un año después de que Pío VII restableciese la Compañía de Jesús, el rey de España, Fernando VII, mediante su Real Decreto de 29 de mayo abolía, revocaba y anulaba la Pragmática Sanción de 2 de abril de 1767 y todas las leyes y reales órdenes que se expidieron con posterioridad, con el objetivo de que tuviese lugar el restablecimiento parcial de la Compañía de Jesús en sus dominios. La Real Cédula de 10 de septiembre del mismo año ordenaba que los hijos de San Ignacio fuesen admitidos y hospedados en sus antiguas casas y colegios que se encontrasen sin destino o aplicación, mandando a las juntas superiores de la Real Hacienda, a la vez, la suspensión de la enajenación o aplicación de las casas, colegios y demás temporalidades que existiesen, para que pudieran ser devueltas a los jesuitas a su debido tiempo.

El rey era consciente de que el Consejo no podría ocuparse del modo que era más conveniente y deseable del restablecimiento de los jesuitas, debido a sus múltiples y primordiales ocupaciones, por lo que el 19 de octubre de 1815 ordenaba la creación de una junta de ministros de confianza, procedentes de los Consejos de Castilla, Indias, Órdenes y Hacienda, para que se dedicase exclusivamente de la restauración de los miembros de la Compañía de Jesús.

El 22 de diciembre de dicho año, Fernando VII ordenaba el cese de la Junta del crédito público en todo lo que tuviese que ver con los bienes de los jesuitas, quedando su dirección y administración a cargo de la Contaduría general de las temporalidades, como lo estuvo en tiempos

${ }^{49}$ Tomás y Valiente, Francisco 1977: 52-54. 
anteriores, bajo la supervisión de la Junta de restablecimiento. La Dirección del crédito público debía entregar todo el dinero y los documentos que pertenecieran a esta materia al contador general de dicho ramo, Casiano Manuel González de Castro. Además, debía ocuparse de formar un informe en el que constasen los créditos que resultasen a favor y en contra de las temporalidades, tanto activos como pasivos, a fin de que la junta pudiese acordar las órdenes pertinentes para la recaudación y pago de los mismos. ${ }^{50}$

La real cédula que contemplaba el restablecimiento general de la Orden llegó con fecha de 3 de mayo de 1816. Además de permitir la vuelta de los jesuitas a todos sus dominios, Fernando VII mandaba que se les devolviesen las

"Casas, Colegios, Iglesias, Hospicios, Residencias, bienes y rentas que se la ocuparon al tiempo de la expulsión y se hallan existentes en la actualidad, con obligación de cumplir las cargas de enseñanza y demas de justicia á que esten afectos, y se declaren corresponderles".

De la devolución de sus propiedades se exceptuaban

"las fincas, bienes y efectos vendidos ó de cualquier modo enagenados por título y causa onerosa á favor de cuerpos ó particulares, y los donados ó aplicados á objetos y establecimientos públicos que no puedan separarse de ellos sin menoscabo de los mismos y ofensa de la comun utilidad".

En el caso de los dominios ultramarinos, el monarca ordenó la expedición de una orden circular a los virreyes, capitanes generales, gobernadores, Reales Audiencias y, en definitiva, a las autoridades de América y de las islas Filipinas, para que, en primer lugar, reconociesen la autoridad de la Junta de restablecimiento $y$, seguidamente, propusiesen, de acuerdo con las autoridades eclesiásticas, los lugares en los que fuese más conveniente el restablecimiento de los jesuitas, pues por el momento, su reducido número les impediría poblar todos los colegios que poseyeron antes del extrañamiento.

Los virreyes, presidentes, gobernadores y Reales Audiencias quedaban encargados de elaborar un estado general de las

${ }^{50}$ Ídem. 
temporalidades en el que se expresase lo que se debía cobrar, lo cobrado y lo existente, a fin de que la Junta de restablecimiento tuviese conocimiento de la actividad o morosidad en la administración y se dictasen las órdenes oportunas. Igualmente, deberían remitir todos los fondos que perteneciesen a las temporalidades y existiesen en sus dominios.

De esta forma, los bienes de los jesuitas, que por tantas y tan diferentes manos habían pasado a lo largo de todos estos años, deberían volver a sus legítimos dueños, si bien es cierto que no siempre se les pudieron restituir los inmuebles de sus colegios, y que en esto no ayudo en absoluto el hecho de que poco tiempo después de su restablecimiento se ordenase una nueva expulsión de la Orden con la llegada al poder de los liberales en 1820.

\section{BIBLIOGRAFÍA}

AGS, Dirección General del Tesoro, Inventario 27.

Alberola, Armando y Giménez, Enrique. 1982. "Las temporalidades de la Compañía de Jesús en Alicante". Revista de Historia Moderna. Anales de la Universidad de Alicante 2: 167-210.

Archivo Campomanes, 45/3.

Archivo General de Simancas, Gracia y Justicia, leg. 1009.

Azagra, Joaquín. 1986. La desamortización de Godoy en Valencia (1799-1807), Valencia: Institució Valenciana d'Estudis i Investigació.

Castro, Concepción de. 1996. Campomanes. Estado y reformismo ilustrado. Madrid: Alianza Editorial.

Coleccion general de las providencias hasta aquí tomadas sobre el estrañamiento y ocupacion de temporalidades de los regulares de la Compañia, que existian en los Dominios de S.M. de España, Indias, e Islas Filipinas á consequencia del Real Decreto de 27 de Febrero y Pragmática-Sancion de 2 de abril de 1767. 
Corona, Carlos E. 1975. "Sobre el Conde de Aranda y sobre la expulsión de los jesuitas", en Homenaje al Dr. D. Juan Reglá, vol. 2: 79106, Valencia: Universidad de Valencia, Facultad de Filosofía y Letras.

Egido, Teófanes. 1976. "Motines de España y proceso contra los jesuitas". Estudio Agustiniano 11: 219-260.

Egido, Teófanes y Pinedo, Isidoro. 1994. Las causas "gravísimas" y secretas de la expulsión de los jesuitas por Carlos III. Madrid: Fundación Universitaria Española.

Fernández Arrillaga, Inmaculada 2004. El destierro de los jesuitas castellanos (1767-1815). Valladolid: Junta de Castilla y León.

Fernández Arrillaga, Inmaculada 2006. "El extrañamiento de los jesuitas valencianos", en E. Giménez (ed.), De cosas y hombres de nación valenciana. Doce estudios en homenaje al Dr. Antonio Mestre Sanchís: 341-375, Alicante: Publicaciones de la Universidad de Alicante.

Fernández Arrillaga, Inmaculada. 2007. "El exilio de los jesuitas Andaluces", en J. Morales y A. Galán (eds.), La Compañía de Jesús en España: otra mirada: 107-128. Madrid: Grupo Anaya.

García Trobat, Pilar. 1992. La expulsión de los jesuitas, Valencia: Generalitat Valenciana.

García Trobat, Pilar. 1999. El patrimonio de los jesuitas en Valencia y su desamortización, Valencia: Bèrnia Edicions.

Gazeta de Madrid, martes 2 de octubre de 1798.

Giménez López, Enrique. 1997. "El ejército y la Marina en la expulsión de los jesuitas de España", en E. Giménez (ed.), Expulsión y exilio de los jesuitas españoles: 67-114. Alicante: Publicaciones de la Universidad de Alicante.

Guasti, Niccolò. 2006. Lotta política e riforme all'inizio del regno di Carlo III, Firenze: Alinea.

Irles Vicente, María del Carmen. 1997. "Tomismo y jesuitismo en los tribunales españoles en vísperas de la expulsión de la Compañía", en E. Giménez (ed.), Expulsión y exilio de los jesuitas españoles: 41-66. Alicante: Publicaciones de la Universidad de Alicante. 
López Martínez, Antonio Luis 1988. "El patrimonio económico de los jesuitas en el reino de Sevilla y su liquidación en tiempos de Carlos III". Archivo Hispalense 217: 35-60.

López Martínez, Antonio Luis. 1999. "El patrimonio rústico de los jesuitas en España. Una aproximación". Hispania 203: 925-954.

Martínez Tornero, Carlos A. 2008. "Las temporalidades jesuitas. Aproximación al funcionamiento administrativo después de la expulsión de la Compañía de Jesús en 1767", en Esteban de Terreros y Pando: vizcaíno, polígrafo y jesuita. III Centenario: 1707-2007: 537-562, Bilbao: Deusto publicaciones.

Martínez Tornero, Carlos A. 2010. Carlos III y los bienes de los jesuitas. La gestión de las temporalidades por la monarquía borbónica (1767-1815), Alicante: Publicaciones de la Universidad de Alicante.

Mateos, F. 1967. "Notas Históricas sobre el antiguamente llamado 'Archivo de las temporalidades' de jesuitas", en A. Guglieri Navarro, Documentos de la Compañía de Jesús en el Archivo Histórico Nacional, Madrid: Razón y Fe.

Pérez y López, Antonio Javier. 1797. Teatro de la Legislación universal de España e Indias. Madrid.

"Real Cédula de SM y señores del Consejo en que se manda guardar y cumplir el Real Decreto que se cita, por el qual se crea una Superintendencia general de Temporalidades ocupadas á los Regulares que fuéron de la extinguida Compañía, y tambien una Direccion general de este ramo, que baxo la autoridad de dicha Superintendencia se encargue de su gobierno; en la conformidad que se expresa. Año 1797. En Madrid, en la Imprenta Real".

"Real Cédula de SM y señores del Consejo en que se nombra al obispo de Salamanca gobernador del Consejo, para que dirija y entienda en los negocios de temporalidades ocupadas á los Regulares de la extinguida Compañía, con las mismas ámplias y convenientes facultades concedidas á su antecesor. Año 1795. En Madrid, en la imprenta de la viuda é hijo de Marín".

"Real Cédula de SM y señores del Consejo, por la qual se manda cumplir el Decreto inserto, en que se nombra al Conde de la Cañada Gobernador del Consejo, para que dirija y entienda en los negocios de 
Temporalidades ocupadas á los Regulares de la extinguida Compañia, con todas las facultades amplias y convenientes para que mande llevar á efecto lo resuelto en este asunto. En Madrid, año 1792, en la imprenta de la Viuda e Hijo de Marin".

Reguera Valdelomar, Juan. 1810. Peticiones sobre reparo de agravios causados en el fatal reinado de Carlos IV. Dirigidas a la Nación española reunida y representada en Cortes generales. Madrid.

Rodríguez de Campomanes, Pedro. 1977. Dictamen fiscal de la expulsión de los jesuitas de España (1766-1767). Edición, introducción y notas de Jorge Cejudo y Teófanes Egido, Madrid: Fundación Universitaria Española.

Tomás y Valiente, Francisco. 1977. El marco político de la desamortización en España. Barcelona: Ariel.

Yun Casalilla, Bartolomé. 1986. "La venta de los bienes de las temporalidades de la Compañía de Jesús. Una visión general y el caso de Valladolid (1767-1808)", en Desamortización y hacienda pública, vol. 1: 293-316, Ministerio de Agricultura, Pesca y Alimentación, Secretaría General Técnica; Ministerio de Economía y Hacienda; Instituto de Estudios Fiscales.

1802. Recopilación de todas las providencias respectivas á vales reales expedidas desde 1780 . Madrid, en la imprenta de la viuda e hijo de Marín.

1805. Novísima recopilación de las Leyes de España. Madrid

1810. Prontuario de las leyes y decretos del Rey Nuestro Señor José Napoleón I desde el año de 1805. Madrid. 